\title{
Validation of self-administered tests for screening for chronic pregnancy-related pelvic girdle pain
}

Monika Fagevik Olsén 1,2*, Paulina Körnung1', Sophie Kallin', Helen Elden, ${ }^{3,4}$ Gunilla Kjellby Wendt1,2 and Annelie Gutke ${ }^{1}$

\begin{abstract}
Background: Many women develop pelvic girdle pain (PGP) during pregnancy and about 10\% have chronic pain several years after delivery. Self-administered pain provocation tests are one way to diagnose and evaluate this pain. Their validity in post-partum women is not yet studied.

The purpose of this study was to evaluate the validity of self-administered test for assessment of chronic pregnancy-related PGP several years after delivery.

Methods: Women who previously have had PGP during pregnancy and who participated in one of three RCT studies were invited to a postal follow up of symptoms including performance of self-administered tests after two, 6 or 11 years later, respectively. In total, 289 women returned the questionnaire and the test-results. Of these, a subgroup of 44 women with current PGP underwent an in-person clinical examination. Comparisons were made between test results in women with versus without PGP but also, in the sub-group, between the self-administered tests and those performed during the clinical examination.

Results: Fifty-one women reported PGP affecting daily life during the last 4 weeks, and 181 reported pain when performing at least one of the tests at home. Those with chronic PGP reported more positive tests $(p<0.001)$. There was no significant difference between diagnosis from the self-administered tests compared to tests performed during the in-person clinical examination $(p=0.305)$, either for anterior or posterior PGP. There were no significant differences of the results between the tests performed self-administered vs. during the clinical examination.

Conclusion: A battery of self-administered tests combined with for example additional specific questions or a paindrawing can be used as a screening tool to diagnose chronic PGP years after delivery. However, the modified SLR test has limitations which makes its use questionable.
\end{abstract}

Keywords: Chronic, Pelvic girdle pain, Postpartum, Provocation tests

\footnotetext{
* Correspondence: monika.fagevik-olsen@vgregion.se

'Department of Health and Rehabilitation/Physiotherapy, Institute of

Neuroscience and Physiology, Sahlgrenska Academy, University of Gothenburg, S-405 30 Gothenburg, Sweden

${ }^{2}$ Department of Physical Therapy, Sahlgrenska University Hospital, S-413 45

Gothenburg, Sweden

Full list of author information is available at the end of the article
}

C C The Author(s). 2021 Open Access This article is licensed under a Creative Commons Attribution 4.0 International License, which permits use, sharing, adaptation, distribution and reproduction in any medium or format, as long as you give appropriate credit to the original author(s) and the source, provide a link to the Creative Commons licence, and indicate if changes were made. The images or other third party material in this article are included in the article's Creative Commons licence, unless indicated otherwise in a credit line to the material. If material is not included in the article's Creative Commons licence and your intended use is not permitted by statutory regulation or exceeds the permitted use, you will need to obtain permission directly from the copyright holder. To view a copy of this licence, visit http://creativecommons.org/licenses/by/4.0/. The Creative Commons Public Domain Dedication waiver (http://creativecommons.org/publicdomain/zero/1.0/) applies to the data made available in this article, unless otherwise stated in a credit line to the data. 


\section{Background}

More than half of all pregnant women develop pelvic girdle pain (PGP) and/or lumbar pain during or after pregnancy, however, prevalence reported varies greatly depending on diagnostic criteria [1-3]. PGP is defined as pain in the area between the posterior iliac crest and the gluteal fold most common around the sacroiliac joints and/or pubic bone, sometimes with radiating pain in the thighs [3]. The cause of the pain is unclear, but hormonal and biomechanical aspects are thought to have a considerable impact [4]. During pregnancy, the high level of the hormone relaxin makes the pelvic joints more flexible in preparation for delivery. This flexibility increases the demands on muscles and ligaments and increases the risk of pain in the area when muscles do not sufficiently compensate for the increased flexibility [3].

The prevalence for chronic PGP after delivery also varies, with ranges from 8.5 to $37 \%$ and it may persist for decades $[5,6]$. Women with pain in both sacroiliac (SI) joints and the pubic symphysis during pregnancy have the highest risk of developing chronic symptoms [5]. Chronic PGP has major consequences such as reduced ability to perform daily activities and work as well as decreased health-related quality of life [6, 7]. Additionally, they have more problems with sleep and higher levels of anxiety, depression, and pain-catastrophizing thoughts [6].

Predictors for chronic PGP are PGP during previous pregnancy, lumbopelvic pain prior to pregnancy and multiple positive pain provocation tests during examination [6, 8]. According to European guidelines [3] different tests must be performed to diagnose and classify PGP, such as the Posterior Pelvic Pain Provocation Test (P4), Patrick's Faber test, Gaenslen's Test, Modified Trendelenburg Test, and palpation of the pubic symphysis. It is also often recommended to perform the Active Straight Leg Raise Test (ASLR), but only as a functional test [3]. One limitation of these tests is that they must be performed by an examiner. Earlier studies have evaluated incidence and prevalence of PGP by solely selfreported symptom in postal questionnaires [9-11]. However, these results must be interpreted with care as there is an uncertainty about the actual location of their pain as no tests were performed. Self-administered tests have therefore been developed to be used as a screening tool in addition to questions concerning pain and functional limitation [12, 13]. A "self-administered test" refers to a test that a person can perform on her own after verbal or written instructions. Four such tests have been described for posterior PGP: modified P4, Bridging test, modified Trendelenburg test and Patrick Faber's test; two for anterior PGP i.e., for symphyseal pain: the modified Trendelenburg test and the MAT test and two for evaluating function: ASLR and modified SLR [12, 13]. For descriptions of the tests, see below, under Methods.
These self-administered tests have been evaluated in two previous studies in pregnancy [12, 13]. In these studies, it was concluded that modified $\mathrm{P} 4$ and Bridging tests can be used by pregnant women to screen for posterior PGP and that the traditionally used palpation of the symphyseal joint for anterior PGP and could be replaced by pain history, pain drawing and the MAT test as palpation of the symphyseal joint is very painful [12, 13]. In the first trial [12], the pregnant women performed the self-administered tests after on-site instructions and the tests were thereafter directly repeated the traditional way, by an examiner. In the second trial, pregnant women were asked to perform the selfadministered tests at home the day before the appointment with a specialized physiotherapist to assess the symptoms [13]. The results were compared to results of the tests performed during the visit. Both trials included women who visited a specialist clinic $[12,13]$. To date, there are no studies concerning the validity of the selfadministered tests' in patients with chronic PGP after pregnancy.

The purpose of this study was therefore to evaluate the validity of self-administered tests for chronic pregnancy-related PGP among women with or without such pain by analyzing the consistency between the selfadministered tests and subsequent diagnosis set by the self-administered tests and a questionnaire vs. a clinical examination.

\section{Methods}

This is a part of a long-term follow-up of women with previous pregnancy-related PGP [6] who, participated in one of three randomized controlled trials evaluating different treatment modalities two, six, and 11 years previously [6]. In this follow-up 530 women were contacted [6]. The ethics committee at University of Gothenburg, Gothenburg, Sweden approved the study in May 2012 (Dnr 193-12) and the women gave their written informed consent in the questionnaire. Postal questionnaires were sent and the women who consented were asked to return the questionnaire within 2 weeks. Two reminders were sent, four and 6 weeks later respectively, if the questionnaire was not returned. The number of women responding to the survey was 371 (70\%), of which 26 were excluded due to on-going pregnancy or systemic disease, leaving 345 women included in the follow-up [6].

The questionnaire included questions concerning pain and physical function. One of the questions was asked if they have had experienced lumbopelvic pain which had affected their daily life more than 1 day during the last 4 weeks, except for pain because of menstruation or fever. This question is recommended by a modified Delphi study conducted with 28 experts in back pain research 
from 12 countries [14]. The response of the questions was included to be able to divide the women into two groups those with and without chronic pain. The women were also asked to complete a pain drawing and perform self-administered pain provocation tests to reproduce their PGP. In addition, to be able to distinguish between lumbar pain and PGP, self-administered versions of the ASLR and the modified SLR were also added. All tests were carried out bilaterally according to written instructions and drawings/photos [12, 13]:

- Anterior PGP- a positive test had to reproduce pain in the symphyseal area

$\bigcirc$ Modified Trendelenburg test: Standing on one leg, with the other leg in $90^{\circ}$ flexion in hip and knee.

MAT test: Standing on one straight leg, having the opposite leg straight and the foot in constant contact with the floor as the leg is abducted to the side. This is followed by an immediate adduction back to start position, with pressure on the toes. This is simulating the movement "to pull a mat".

- Posterior PGP- a positive test had to reproduce pain around the SI-joints

Modified Trendelenburg test: Standing on one leg, the other in $90^{\circ}$ flexion in hip and knee.

4P test (Posterior Pelvic Pain Provocation test): In the supine position with one leg in $90^{\circ}$ hip flexion, the patient pressed with her hands on the flexed knee, along the longitudinal axis of the femur.

Bridging test: In the supine position with bent knees and the feet on the ground, the buttocks were lifted, and one leg at a time was extended in the air until the hip and knee was in a neutral position.

Patrick Faber's test: In the supine position with one hip flexed, abducted, and rotated so that the heel rested on the opposite kneecap. This position should be maintained for $5 \mathrm{~s}$.

- Additional tests

$\bigcirc$ Modified SLR (Straight Leg Raise test): Sitting with straight legs and $90^{\circ}$ hip flexion. Positive test was reported if radiating pain in either of the legs. $\bigcirc$ ASLR (Active Straight Leg Raise test): In supine position, one leg at a time was raised $20 \mathrm{~cm}$ from the surface. The women reported how difficult it was to raise the leg on a six-point lickert-scale from 0 (no difficulties to perform) to 5 (impossible to perform) and if it caused pain.

Women who reported chronic PGP were offered an in-person clinical examination by a specialized physiotherapist. During the examination, the women were asked about their pain history and what provoked and eased their pain and when. They also underwent an examination to diagnose whether the pain originated from the lumbar or pelvic region or none of these areas [6]. The measuring instrument for assessing mechanical lumbar impact was Mechanical Diagnosis and Therapy [15]. The tests for PGP were the same as the selfadministered tests but instructed/performed traditionally by an examiner $[3,16]$. The PGP diagnosis was set according to the definition in the European guidelines: pain in the SI joints and/or pubic symphysis which had to be reproduced by specific clinical tests performed by an examiner $[3,6]$. Fig 1 shows the flow-chart of the study.

The women were also diagnosed regarding PGP based on the self-administered tests and the questionnaire, according to the same criteria as during the examination [6] but adjusted concerning the tests:

- Self reported PGP during the past 4 weeks affecting daily life during a minimum of 1 day (according to the questionnaire).

- a positive pain-drawing i.e., the area of the SI-joints and/or pubic symphysis was marked.

- at least one positive self-administered test for anterior PGP i.e., symphyseal pain and / or two positive tests for posterior PGP.

Women who reported pain during at least 1 day during the last 4 weeks but had no positive pain provocation tests for the SI-joints or pubic symphysis but reported pain when performing modified SLR and /or ASLR test were classified with lumbar pain.

The consistency between self-administered tests and the tests performed during the clinical visit were analyzed by comparing the results of the tests and subsequent diagnosis in the women who underwent the inperson clinical examination.

The statistical program SPSS version 25 was used for the statistical analysis.

For analysis between the groups (PGP or not) with regards to dichotomous variables (positive and negative tests), a Chi-square test or Fisher's exact test was used and for continuous variables a t-test was used. Sensitivity, specificity, negative predictive value (NPV) and positive predictive value (PPV) were calculated between the self-administered test and the test performed at the clinical examination.

A $p$-value $<0.05$ was defined as significant.

\section{Results}

Of the 345 women who participated in the follow-up, 56 did not perform the self-administered tests leaving 289 


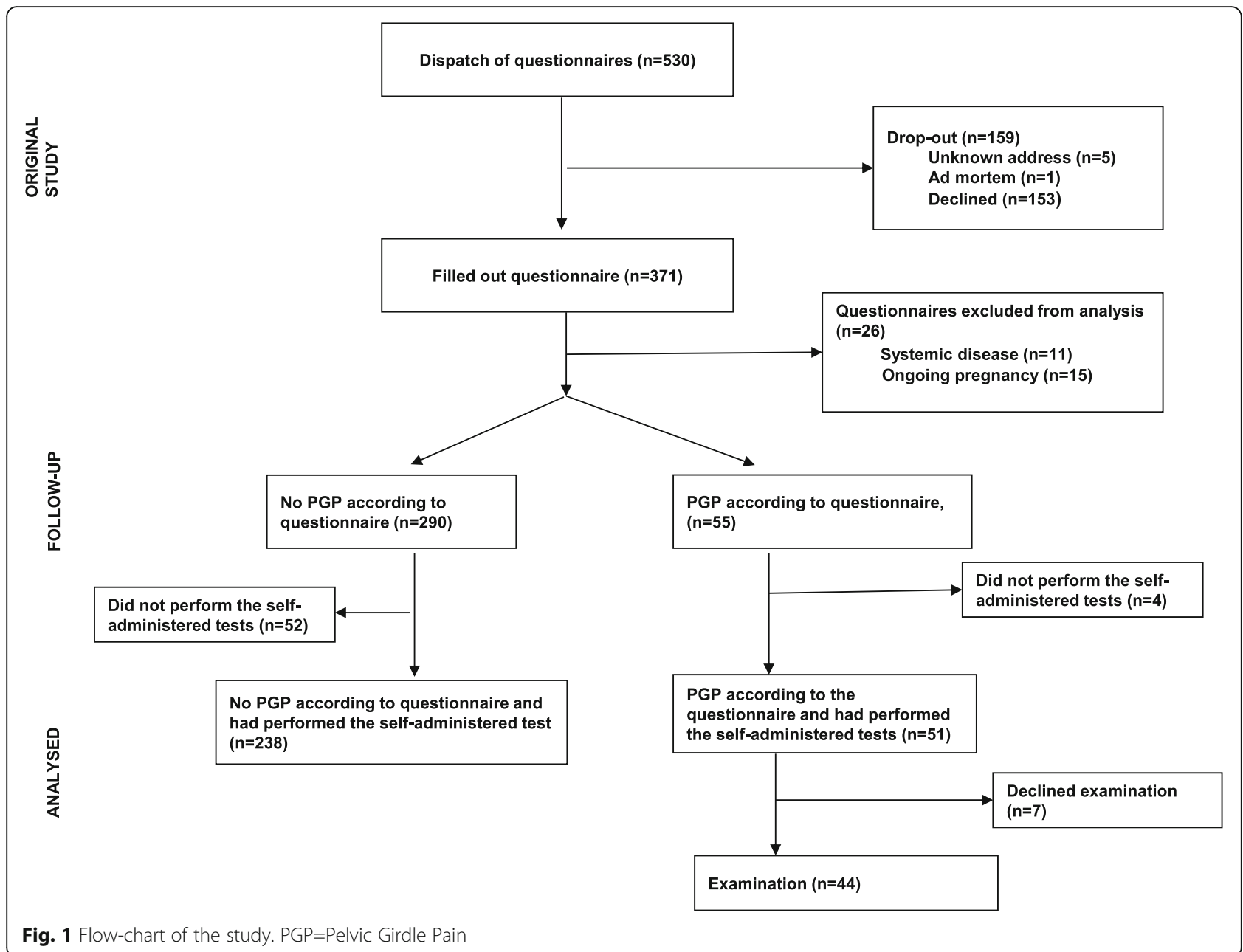

women who were included in this part of the study. Demographic data, in total and for the women with $(n=$ 51) and without $(n=238)$ PGP is presented in Table 1. There were no significant differences between the groups.
Of the 289 women, 181 reported to have at least one positive self-administered test. A positive Patrick Faber test was reported most frequently (27.7\%) followed by the positive $\mathrm{P} 4$ test $(23.5 \%)$ and Bridging test $(20.8 \%)$. There were fewer positive test-results

Table 1 Baseline characteristics of women who 2,6 or 11 years earlier had PGP

\begin{tabular}{|c|c|c|c|c|}
\hline & $\begin{array}{l}\text { Total } \\
n=289\end{array}$ & $\begin{array}{l}\text { Reporting PGP } \\
n=51\end{array}$ & $\begin{array}{l}\text { No PGP } \\
n=238\end{array}$ & $p$-value \\
\hline Age (years), at inclusion & $31.0(4.3)$ & $30.6(3.6)$ & $31.1(4.4)$ & 0.459 \\
\hline Age at follow-up, years & $39.3(5.6)$ & $37.8(4.6)$ & $39.6(5.8)$ & 0.064 \\
\hline Parity (n) & $2(1-6)$ & $2(1-5)$ & $2(1-6)$ & 0.741 \\
\hline Index pregnancy (n) & $3(1-5)$ & $3(1-4)$ & $3(1-5)$ & 0.439 \\
\hline Vaginal delivery (\%) & 82.9 & 79.7 & 91.3 & 0.080 \\
\hline $\begin{array}{l}\text { Marital status } \\
\text { Married or cohabiting/Single (\%) }\end{array}$ & $91 / 9$ & $91 / 9$ & $91 / 9$ & 0.906 \\
\hline Body Mass Index $\left(\mathrm{kg} / \mathrm{m}^{2}\right)$ & $24.7(4.1)$ & $24.7(4.3)$ & $24.7(4.0)$ & 0.942 \\
\hline Days of physical activity/ week (n) & $4(0-7)$ & $3(0-7)$ & $4(0-7)$ & 0.725 \\
\hline
\end{tabular}

Mean ( \pm SD) or median (min-max). 
Table 2 Results of positive self-administered pain provocation tests

\begin{tabular}{|c|c|c|c|c|c|c|c|c|}
\hline \multirow[t]{2}{*}{ Self-administered test } & \multicolumn{3}{|c|}{ Number of positive tests } & \multirow[b]{2}{*}{$p$-value between groups } & \multirow[b]{2}{*}{ Sensi-tivity } & \multirow[b]{2}{*}{ Speci-ficity } & \multirow[b]{2}{*}{ NPV } & \multirow[b]{2}{*}{ PPV } \\
\hline & $\begin{array}{l}\text { Total } \\
n=289\end{array}$ & $\begin{array}{l}\text { PGP } \\
n=51\end{array}$ & $\begin{array}{l}\text { No PGP } \\
n=238\end{array}$ & & & & & \\
\hline \multicolumn{9}{|l|}{ Tests for anterior pgp } \\
\hline Trendelenburg, symphyseal pain & $16(5.5 \%)$ & $9(17.6 \%)$ & 7 (2.9\%) & 0.001 & 17.6 & 2.9 & 84.6 & 56.3 \\
\hline MAT & $24(8.3 \%)$ & $12(23.5 \%)$ & $12(5.0 \%)$ & $<0.001$ & 23.5 & 5.0 & 85.3 & 50.0 \\
\hline \multicolumn{9}{|l|}{ Tests for posterior pgp } \\
\hline Trendelenburg, posterior pain & $46(15.9 \%)$ & 25 (49.0\%) & $21(8.8 \%)$ & $<0.001$ & 49.0 & 8.8 & 84.8 & 54.3 \\
\hline P4 & $68(23.5 \%)$ & $29(56.9 \%)$ & $39(16.3 \%)$ & $<0.001$ & 56.9 & 16.4 & 90.0 & 42.6 \\
\hline Bridging & $60(20.8 \%)$ & $29(56.9 \%)$ & $31(13.0 \%)$ & $<0.001$ & 56.9 & 13.0 & 90.4 & 48.3 \\
\hline Patrick Faber & $80(27.7 \%)$ & $31(60.8 \%)$ & $49(20.6 \%)$ & $<0.001$ & 60.8 & 20.5 & 90.9 & 51.7 \\
\hline Total number of positive PGP tests, $0-12$ & $0(0-12)$ & $4(0-12)$ & $0(0-12)$ & $<0.001$ & & & & \\
\hline \multicolumn{9}{|l|}{ Additional tests } \\
\hline ASLR, pain & $66(22.8 \%)$ & $30(58.8 \%)$ & $36(15.1 \%)$ & $<0.001$ & 58.8 & 15.1 & 82.9 & 100 \\
\hline ASLR, difficulty & $0(0-8)$ & $2(0-8)$ & $0(0-6)$ & $<0.001$ & & & & \\
\hline Modified SLR & $21(7.3 \%)$ & $11(21.6 \%)$ & $10(4.2 \%)$ & $<0.001$ & 21.6 & 4.2 & 85.1 & 52.4 \\
\hline
\end{tabular}

Sensitivity: proportion of positives that are correctly identified by the test.

Specificity: proportion of negatives that are correctly identified by the test.

NPV (Negative Predictive Value): proportion of patients with a positive test who are correctly diagnosed.

PPV (Positive Predictive Value): proportion of patients with a negative test who are correctly diagnosed.

P4 Posterior Pelvic Pain Provocation test, ASLR Active Straight Leg Raising test, SLR Straight Leg Raise test, PGP Pelvic Girdle Pain.

reported for tests which provoked pain in the public symphysis region.

The number of positive self-administered tests for the whole group and divided in those with or without PGP are presented in Table 2. There was a significant difference in the number of positive tests between the two groups in all included tests. In addition, the proportion of women with at least one positive test of the bilateral six pelvic pain provocation tests (number of women with a positive test(s)/total number of women in the group) was significantly higher in the group reporting PGP in the last 4 weeks than in those reporting no pain $(p<0.001)$. As only women with chronic pain fulfilled the definition to be diagnosed with PGP, noone in the group with no pain $(n=238)$ was diagnosed with PGP. In this group 159 (67\%) did not report any positive provocation tests in the symphyseal joint or sacroiliac joints. Of the remaining women in that group, one positive test was reported by 21 (9\%), two positive tests by $19(8 \%)$ and $\geq 3$ positive tests by 39 women (16\%).

When applying the criterion of one positive test in the symphyseal joint and/or two in the sacroiliac joint, 51 women $(21 \%)$ reported positive test $(-\mathrm{s})$ according to the definition.

The highest sensitivity, $>55 \%$, was seen in the P4, Bridging test, Patrick Faber's test and ASLR and the lowest for Trendelenburg test for symphyseal pain (17.6\%) and modified SLR (21\%). Specificity was overall low (< 21\%). NPV exceeded $80 \%$ in all tests and PPV was approximately $50 \%$ in all tests except for ASLR for pain which had a specificity of $100 \%$.

Among the 51 women with chronic pain, 44 (86\%) were clinically diagnosed as having PGP based on the criteria for PGP and positive pain provocation tests. Two women had solely anterior pain in the symphyseal joint, 30 had posterior pain in the sacroiliac joints and 12 had pain both in the anterior and posterior pelvic girdle.

The results of the tests and the subsequent diagnosis from the 44 women who performed the selfadministered tests and thereafter the in-person clinical examination are included in Table 3. There were no significant differences between the groups in the proportion of positive tests. There were no significant differences between the diagnosis set after selfadministered tests and questionnaire and diagnosis set at the clinical follow up in anterior PGP (0.676), posterior PGP test $(p=0.209)$ or diagnosis of PGP $(p=0.305)$.

\section{Discussion}

The main finding from this study is that there is no significant difference between the diagnosis of PGP by selfadministered tests and a questionnaire versus diagnosis after an in-person clinical examination in women with chronic PGP up to 11 years after pregnancy. This was found for both posterior PGP and anterior PGP. In other words, the battery of self-administered tests is valid and can be used as a screening tool by the woman or 
Table 3 Positive tests and diagnosis of PGP by self-administered tests or tests performed during the in-person clinical examination

\begin{tabular}{|c|c|c|c|c|}
\hline \multicolumn{2}{|l|}{ Test } & $\begin{array}{l}\text { Positive self-administered } \\
\text { tests, } n=44\end{array}$ & $\begin{array}{l}\text { Positive tests during the in-person clinical } \\
\text { examination, } n=44\end{array}$ & $\begin{array}{l}P \text {-value between the } \\
\text { groups }\end{array}$ \\
\hline \multicolumn{2}{|c|}{ Trendelenburg, symphyseal pain } & 8 & 12 & $>0.999$ \\
\hline \multicolumn{2}{|l|}{ MAT-test } & 11 & 17 & 0.724 \\
\hline \multicolumn{2}{|c|}{ Trendelenburg, posterior pain } & 21 & 14 & 0.197 \\
\hline \multicolumn{2}{|l|}{ P4 } & 24 & 31 & 0.341 \\
\hline \multicolumn{2}{|l|}{ Bridging } & 22 & 20 & 0.121 \\
\hline \multicolumn{2}{|l|}{ Patrick Faber } & 29 & 13 & 0.164 \\
\hline \multicolumn{2}{|c|}{ ASLR, difficulty } & 23 & 26 & 0.650 \\
\hline \multicolumn{2}{|l|}{ SLR } & 8 & 3 & 0.498 \\
\hline \multicolumn{2}{|c|}{ Diagnosed anterior PGP } & 13 & 8 & 0.676 \\
\hline \multicolumn{2}{|c|}{ Diagnosed posterior PGP } & 27 & 27 & 0.209 \\
\hline \multirow{7}{*}{$\begin{array}{l}\text { Diagnosis of } \\
\text { PGP }\end{array}$} & No pain & 0 & 5 & 0.305 \\
\hline & Symphyseal & 3 & 3 & \\
\hline & One sided SI & 2 & 3 & \\
\hline & $\begin{array}{l}\text { One sided SI and } \\
\text { symphyseal }\end{array}$ & 1 & 2 & \\
\hline & Bilateral SI & 16 & 13 & \\
\hline & PGS & 11 & 9 & \\
\hline & Back pain & 11 & 9 & \\
\hline
\end{tabular}

P4 Posterior Pelvic Pain Provocation test, ASLR Active Straight Leg Raising test, SLR Straight Leg Raise test, PGP Pelvic Girdle Pain, PGS Pelvic Girdle Syndrome.

healthcare professionals as an initial evaluation before further assessment and/or referral to treatment.

From our previous studies of the self-administered tests, we learned that the tests can already be used during pregnancy by the pregnant woman herself or by midwives or other health care professionals when pregnant women report PGP at the antenatal unit $[12,13]$. An early diagnosis of PGP during pregnancy may counteract the development of increased pain and decreased function that is commonly seen during pregnancy [17]. The present study shows that the self-administered tests can support identification of chronic PGP after pregnancy as well.

Early identification of PGP is important for a woman's health during pregnancy, as back pain including PGP is one of the most common reported barriers to being physically active in pregnancy $[18,19]$. Early identification and intervention of PGP may prevent lower physical activity levels and low functioning of daily activities caused by pain, which is commonly reported by pregnant women [20]. Chronic PGP is a reality for many women in the world, and causes not only suffering for the woman herself, but also her family and society more broadly $[6,21,22]$.

In general, sensitivity was higher than specificity for all pain provocation tests, which indicates that PGP was identified by the battery of self-administered tests. Since it is important to identify PGP early in its course, to prevent long term pain [6], the higher risk of false positive are to be preferred as compared to false negatives, so women with PGP are not missed.

Taking the present study and our previous studies of self-administered test into account, the $\mathrm{P} 4$ and the Bridging test can be recommended for identification of posterior PGP [12, 13]. Although good clinometric on the Patrick Faber's test was seen in the present study, inconsistence was found compared to findings in our previous two studies [12, 13]. From an anatomic point of view, the test involves both hip, pelvis and lumbar spine. There is disagreement on the reliability of the Patrick Faber's test according to European guidelines [3]. The test result may be too difficult for non-professionals to interpret and therefore we cannot recommend it as a self-administered test.

For identification of anterior PGP i.e., symphyseal pain, the MAT test showed higher sensitivity compared to the Trendelenburg test in the present study, which is in accordance with one of our previous studies [12], but not with the other [13]. More women were identified with symphyseal pain at the in-person clinical examination as compared to the self-administered tests, but the differences were not significant different. Even if one single test results may identify symphyseal pain, the test needs to be combined with other tests, additional specific questions or a pain-drawing to increase sensitivity of the diagnosis. 
In our previous study on the functional selfadministered ASLR [13], fewer positive tests were seen when performed as an in-patient clinical examination compared to the self-administered tests. In contrast, the present study showed no differences between the variants of the tests. Since there are discrepancies between studies, we cannot safely recommend the selfadministered ASLR. This is in accordance with the conclusion stated above that it may be too hard for nonprofessionals to interpret the test result of ASLR [13].

The ASLR and the modified SLR used in the present study do not belong to the pelvic pain provocation tests but are included in the survey as a self-administered test to distinguish between lumbar and / or PGP as recommended [3]. The self-administered ALSR test is like the test performed at the clinical examination but the modified version of SLR is performed in a different position. The modification was utilized as we believe that the change in position reproduces the movement but is easier to perform at home. In our previous study [13], we saw that women registered positive self-administered modified SLR tests that could not be confirmed at the clinic testing. With the present study, we confirm that modified SLR is a difficult test to interpret for a nonprofessional. Based on the results from the present study and our previous studies, we cannot recommend the modified version used in this trial.

There are some limitations of the trial. During the previous evaluations of the self-administered tests pregnant women were included, and the tests were performed at the clinic or the day before the visit to the clinic [12, 13]. In this trial we do not know how many days before the visit the women performed the tests at home; for some women it was weeks between when they performed the self-administered tests until they were tested again during their clinic appointment. There is a risk that this delay has interfered with the results. On the other hand, the significant differences in test results between the groups, with and without PGP seems to verify that the tests are not only valid when performed during pregnancy but also in chronic PGP.

Even though the self-administered tests were performed after written instructions and photos/illustrations, there is a risk that they were incorrectly performed which is a limitation. Another possibility is to use digital platforms where the tests can be presented by short films. The tests may then be disseminated and subsequently performed wherever or whenever needed.

Future trials are needed to further evaluate the use of self-administered tests in different groups of patients for instance as screening for PGP early in pregnancy. Use of different instruction methods also need to be investigated to find the optimal way to describe how to perform the test in a correct way.
This study is the first to present validation of the selfadministered tests to diagnose chronic PGP. Based on the results from previous studies of the self-administered tests, there is now a good reason to use these tests in clinical practice during and after pregnancy $[6,12,13]$.

\section{Conclusion}

A battery of self-administered tests combined with for example additional specific questions or a pain-drawing can be used as a screening tool to diagnose chronic PGP years after delivery. However, the modified SLR test has limitations which makes its use questionable.

\section{Authors' contributions}

MFO, HE, AG, GKW participated in the design and funding applications. H. E, A. G and G.K.W contributed to data collection. PK, SK and MFO processed the data. All authors participated in interpretation of the results and drafting of the article. All authors read and approved the final manuscript.

\section{Funding}

This study was supported by grants from the Foundation of the Health and Medical care committee of the Region of Vastra Gotaland, Sweden: VGFOUREG-294331, VGFOUREG-294871, and VGFOUREG-381421. Open Access funding provided by University of Gothenburg.

\section{Availability of data and materials}

The datasets used and analyzed during the current study are available from the corresponding author on reasonable request.

\section{Declarations}

Ethics approval and consent to participate

The ethics committee at University of Gothenburg, Gothenburg, Sweden approved this follow-up study in May, 2012 (Dnr 193-12). All research was performed in accordance with relevant guidelines/regulations. The women gave their consent when returning the questionnaire in this follow-up study.

Consent for publication

Not applicable.

\section{Competing interests}

None declared.

\section{Author details}

${ }^{1}$ Department of Health and Rehabilitation/Physiotherapy, Institute of Neuroscience and Physiology, Sahlgrenska Academy, University of Gothenburg, S-405 30 Gothenburg, Sweden. ²Department of Physical Therapy, Sahlgrenska University Hospital, S-413 45 Gothenburg, Sweden. ${ }^{3}$ Institute of Health and Caring Sciences, Sahlgrenska Academy, University of Gothenburg, Sahlgrenska Academy, S-405 30 Gothenburg, Sweden.

${ }^{4}$ Department of Obstetrics and Gynecology, Institute of clinical sciences, Sahlgrenska Academy, University of Gothenburg, Gothenburg, Sweden.

Received: 18 November 2020 Accepted: 18 February 2021 Published online: 01 March 2021

\section{References}

1. Gutke A, Ostgaard HC, Oberg B. Pelvic girdle pain and lumbar pain in pregnancy: a cohort study of the consequences in terms of health and functioning. Spine (Phila Pa 1976). 2006;31(5):E149-55.

2. Wu WH, Meijer OG, Uegaki K, Mens JM, van Dieen JH, Wuisman PI, et al. Pregnancy-related pelvic girdle pain (PPP), I: Terminology, clinical presentation, and prevalence. Eur Spine J. 2004;13(7):575-89.

3. Vleeming A, Albert HB, Ostgaard HC, Sturesson B, Stuge B. European guidelines for the diagnosis and treatment of pelvic girdle pain. Eur Spine J. 2008;17(6):794-819.

4. Vermani E, Mittal R, Weeks A. Pelvic girdle pain and low back pain in pregnancy: a review. Pain Pract. 2010;10(1):60-71. 
5. Albert $\mathrm{H}$, Godskesen $\mathrm{M}$, Westergaard J. Prognosis in four syndromes of pregnancy-related pelvic pain. Acta Obstet Gynecol Scand. 2001;80(6):50510.

6. Elden H, Gutke A, Kjellby-Wendt G, Fagevik-Olsen M, Ostgaard HC Predictors and consequences of long-term pregnancy-related pelvic girdle pain: a longitudinal follow-up study. BMC Musculoskelet Disord. 2016;17:276.

7. Olsson C, Nilsson-Wikmar L. Health-related quality of life and physical ability among pregnant women with and without back pain in late pregnancy. Acta Obstet Gynecol Scand. 2004;83(4):351-7.

8. Robinson HS, Mengshoel AM, Veierod MB, Vollestad N. Pelvic girdle pain: potential risk factors in pregnancy in relation to disability and pain intensity three months postpartum. Man Ther. 2010;15(6):522-8.

9. Bergström C, Persson M, Mogren I. Psychosocial and behavioural characteristics in women with pregnancy-related lumbopelvic pain 12 years postpartum. Chiropr Man Therap. 2019:27:34.

10. Mogren IM, Pohjanen Al. Low back pain and pelvic pain during pregnancy: prevalence and risk factors. Spine. 2005;30(8):983-91.

11. Stafne SN, Salvesen KÅ, Romundstad PR, Stuge B, Mørkved S. Does regular exercise during pregnancy influence lumbopelvic pain? A randomized controlled trial. Acta Obstet Gynecol Scand. 2012;91(5):552-9.

12. Fagevik Olsen M, Gutke A, Elden H, Nordenman C, Fabricius L, Gravesen M, et al. Self-administered tests as a screening procedure for pregnancy-related pelvic girdle pain. Eur. Spine J. 2009;18(8):1121-9.

13. Fagevik Olsen M, Elden H, Gutke A. Evaluation of self-administered tests for pelvic girdle pain in pregnancy. BMC Musculoskelet Disord. 2014;15(1):138.

14. Dionne CE, Dunn KM, Croft PR, Nachemson AL, Buchbinder R, Walker BF, et al. A consensus approach toward the standardization of back pain definitions for use in prevalence studies. Spine. 2008;33(1):95-103.

15. Gutke A, Kjellby-Wendt G, Oberg B. The inter-rater reliability of a standardised classification system for pregnancy-related lumbopelvic pain. Man Ther. 2009;15(1):13-8.

16. Albert $\mathrm{H}$, Godskesen $\mathrm{M}$, Westergaard J. Evaluation of clinical tests used in classification procedures in pregnancy-related pelvic joint pain. Eur. Spine J. 2000;9(2):161-6.

17. Virgara R, Maher C, Van Kessel G. The comorbidity of low back pelvic pain and risk of depression and anxiety in pregnancy in primiparous women. BMC pregnancy and childbirth. 2018:18(1):288

18. Cramp AG. Bray SR. a prospective examination of exercise and barrier selfefficacy to engage in leisure-time physical activity during pregnancy. Annals of behavioral medicine: a publication of the society of. Behav Med. 2009; 37(3):325-34.

19. Haakstad LA, Voldner N, Bo K. Stages of change model for participation in physical activity during pregnancy. J Pregnancy. 2013;1:193170.

20. Evenson KR, Aytur SA, Borodulin K. Physical activity beliefs, barriers, and enablers among postpartum women. J Women's Health (Larchmt). 2009; 18(12):1925-34

21. Wuytack F, Curtis E, Begley C. Experiences of first-time mothers with persistent pelvic girdle pain after childbirth: descriptive qualitative study. Phys Ther. 2015;95(10):1354-64

22. Backhausen M, Damm P, Bendix J, Tabor A, Hegaard H. The prevalence of sick leave: reasons and associated predictors - a survey among employed pregnant women. Sex Reprod Healthc. 2018;15:54-61.

\section{Publisher's Note}

Springer Nature remains neutral with regard to jurisdictional claims in published maps and institutional affiliations.

Ready to submit your research? Choose BMC and benefit from:

- fast, convenient online submission

- thorough peer review by experienced researchers in your field

- rapid publication on acceptance

- support for research data, including large and complex data types

- gold Open Access which fosters wider collaboration and increased citations

- maximum visibility for your research: over $100 \mathrm{M}$ website views per year

At $\mathrm{BMC}$, research is always in progress.

Learn more biomedcentral.com/submissions 